\title{
The Relationship Between Death Depression and Death Anxiety with Coping Style Among CHD Patients
}

\author{
Hadi Hassankhani, ${ }^{1}$ Koroush Rashidi, ${ }^{2,3,}{ }^{*}$ Azad Rahmani, ${ }^{4}$ Farahnaz Abdullahzadeh, ${ }^{2}$ Ali \\ Golmohammadi, ${ }^{5}$ Shadi Ozairi, ${ }^{6}$ and Erfan Ayubi ${ }^{7}$ \\ ${ }^{1}$ Center of Qualitative Studies, Tabriz University of Medical Sciences, Tabriz, Iran \\ ${ }^{2}$ School of Nursing and Midwifery, Tabriz University of Medical Sciences, Tabriz, Iran \\ ${ }^{3}$ Student Research Committee, Tabriz University of Medical Sciences, Tabriz, Iran \\ ${ }^{4}$ Cancer Research Center, Tabriz University of Medical Sciences, Tabriz, Iran \\ ${ }^{5}$ Heart Research Center, Tabriz University of Medical Sciences, Tabriz, Iran \\ ${ }^{6}$ Student Research Committee, Kurdistan University of Medical Sciences, Kurdistan, Iran \\ ${ }^{7}$ Department of Epidemiology and Biostatistics, School of Public Health, Tehran University of Medical Sciences, Tehran, Iran \\ "Corresponding author: Koroush Rashidi, School of Nursing and Midwifery, Tabriz University of Medical Sciences, Tabriz, Iran. Tel: +98-9371172140, E-mail: \\ rashidi_ko@yahoo.com
}

Received 2015 September 12; Revised 2015 December 18; Accepted 2016 September 29.

\begin{abstract}
Objectives: This study aimed to unveil the effect of depression death and anxiety death on coping style among coronary heart disease (CHD) patients in Tabriz, a city in the Northwest of Iran.

Materials and Methods: In this cross-sectional study, 293 coronary heart disease patients were recruited from three hospitals in Tabriz from January to July 2015. Socio-demographic characteristics and CHD clinical history were archived by a checklist. Validated self-administered questionnaires were used to measure death depression, death anxiety, and coping style. The association between death depression and death anxiety with coping style was evaluated, using multivariable linear regression.

Results: In this study, the participants were $60 \pm 11$ years of age. Death depression was most significantly influenced by occupation, and the death anxiety level was affected by the history of hospitalization with CHD. The coping style level was not statistically significant across sociodemographic and CHD clinical history characterises. In death depression, the third quartile was significantly and inversely associated with coping style, compared to reference category; $\beta(95 \% \mathrm{CI}) ;-1.60$ ( -2.97 to -0.27$)$, P value $=0.02$.

Conclusions: Among CHD patients, death depression and death anxiety could be influenced by sociodemographic and CHD history background characteristics, respectively. Death depression could be considered as a determinant for coping style.
\end{abstract}

Keywords: Anxiety Disorders, Coping Behaviour, Coronary Disease, Depressive Disorder, Iran

\section{Background}

Coronary heart disease (CHD) is one of the most common types of cardiovascular diseases and the leading cause of death worldwide (1). According to one of the latest reports in Iran, CHD was the leading cause of death among people aged over 35 years (2). It has been found that CHD also affects emotional, mental, social, and economic conditions of the patients. In other words, heart injuries, not only create physical symptoms and disabilities, but also have a harmful effect on the mental state of a person dealing with it, and may result in psychological stresses such as death depression, death anxiety and coping style dysfunction $(3,4)$.

It has been acknowledged that death depression and death anxiety could be equivalent entities (5). Death anxiety and death depression are the results of conceptualizing the presentiment generated by death notification. Death anxiety is a complex matter, and there is debate be- tween psychiatrists and psychologists about its definition, determinants and treatment. However, it refers to the state in which an individual, stimulated by knowledge of own death, experiences emotional reactions such as apprehension $(6,7)$. Death anxiety describes realization of risk to life in daily events more than acute conditions. Death anxiety has multidimensional features, which contain anticipation of death (8). However, in addition to death anxiety, other emotions and attitudes around death's domain such as depression should be considered. Suffering, hopelessness, loss, and sadness may occur as depressive components in response to death (9).

Coping styles are the behaviors, thoughts, and emotions that we use to respond to psychological stress. There are many coping styles that some may prove more effective than others, depending on the nature of the stressful situation and the person who is employing them. Ineffective coping mechanisms, also referred to as maladaptive coping, may be applied to stressful events or internal 
conflicts. Coping styles are commonly assigned broad categories that draw distinctions between methods. For example, instrumental coping (referred to as problem-solving) focuses on ways to tackle the issue to reduce stress around a given situation, while emotion-focused coping gathers tools to nurture one's emotional health during a stressful period (10-12).

Many studies have revealed that death depression and death anxiety are common among patients with CHD (13, 14). Death anxiety and death depression can also increase the risk of cardiovascular death in these patients, and ignoring them can decrease the chance of successful recovery and reduce recovery from other risk factors for heart disease (15).

It has been identified that demographic, socioeconomic status (SES), and some CHD background variables are associated with the level of death anxiety or death depression, so that female gender, socially disadvantaged, lower education, suitable religious beliefs and physical health are moderately to strongly associated with lower death anxiety and other psychological problems (16-18). On the other hand, the coping literature reveals that the association between coping style and SES is inconsistent (19). Review of studies indicates inconsistency of the results with regards to the relationship between psychological problems and coping style. Some studies in different contexts revealed that coping style dominants could be a function of depression or fear of death, so that death depression could predict how well patients cope with their disease $(20,21)$. In studies that examined the relationship between coping attitudes and anxiety, it was found that individuals with anxiety symptoms or disorders did not have effective coping mechanisms (22).

In many clinical settings, the relationship between death depression and death anxiety with coping style have been investigated in patients with chronic, or terminal illnesses such as cancer or HIV/AIDS (18), but the evidence on CHD context is scarce.

\section{Objectives}

The aim of this study was to examine the effect of sociodemographic factors along with some CHD clinical history characteristics on depression death, anxiety death and coping style, and to find how death depression and death anxiety affect coping style among CHD patients.

\section{Materials and Methods}

\subsection{Participants}

This was a cross-sectional study conducted from January to July 2015 in Tabriz, Iran. A two- stage random sam- pling procedure was used to recruit the patients, and three teaching hospitals of Tabriz University of Medical Sciences (Aali Nasab, Shahid Madani, and Shahid Mahalati) were considered as strata. A simple random sampling was conducted considering the proportion to size of patients in the hospitals.

Among the patients who were eligible to be included in the study, 293 patients completed the self-administered questionnaires through a structured interview. The inclusion criteria were as follows: Age 18 and older, ability to complete the questionnaires or interviews, being hospitalized in one of the wards in the hospitals under study, and willing to participate in the study.

\subsection{Data Collection Materials}

The required data were collected, using sociodemographic and CHD clinical history checklist, Templer's death anxiety, death depression scale, and template questionnaires (23) and Lazarus "ways of coping" questionnaire (24). Templer's death anxiety is a 15- item self-report questionnaire with yes or no answers. It has been used most frequently to measure death anxiety $(25,26)$. In this scale, psychological and life experience factors related to death are measured.

Templer's death depression questionnaire includes 21 items, ranging from 1 (completely disagree) to 5 (completely agree). It is a psychometric instrument for assessing depression associated with the topic of death. In this scale, death dread, death sadness, death despair and death loneliness were measured. These two questionnaires were validated, using content and face validity. After translating the questionnaires from English into Farsi and resolving any translation-related problems, ten professors from the nursing and midwifery department of Tabriz University of Medical Sciences analyzed and verified the materials of the study. To ensure repeatability and internal consistency, test-retest method was used for 20 patients. The Cronbach's alpha coefficients for death depression and death anxiety were estimated to be 0.71 and 0.71 , respectively. Another study reported the internal consistency coefficient by Cronbach's alpha to be 61 to $79 \%$, and found the reliability of the test-retest to be 59 to $83 \%$ within four weeks (27).

Construct validity was validated by confirmatory factor analysis (CFA). The goodness of fit statistics suggested that the considered pattern for the two questionnaire was fitted on data (for Templer's death anxiety, $\chi^{2}=221.46, \mathrm{df}=$ 24 , $\mathrm{P}$ value $<0.001, \mathrm{CFI}=0.91, \mathrm{GFI}=0.85, \mathrm{NFI}=0.91$ and $\mathrm{RM}-$ SEA $=0.06$ and for Templers death depression, $\chi^{2}=201.28$, $\mathrm{df}=19, \mathrm{P}$ value $<0.001, \mathrm{CFI}=0.89, \mathrm{GFI}=0.86, \mathrm{NFI}=0.89$ and RMSEA = 0.09).

Coping styles questionnaire (CSQ), developed by Lazarus and Folkman, analyzes four problem-focused 
(problem-solving, positive reevaluation, responsibility, and seeking social support), and four emotion-focused coping styles (direct confrontation, self-confrontation, preventive, denial). The coping styles questionnaire includes 66 items on a 5 point Likert scale (Never $=1$, sometimes $=2$, usually $=3$ and almost $=4$ ). In this study, Cronbach's alpha for this questionnaire was 0.71 .

Goodness of fit statistics revealed that the questionnaire was confirmed on data $\left(\chi^{2}=188.51, \mathrm{df}=31, \mathrm{P}\right.$ value $<$ $0.001, \mathrm{CFI}=0.90, \mathrm{GFI}=0.87, \mathrm{NFI}=0.92$ and RMSEA $=0.08$ ). The achieved score for death depression, death anxiety and coping style, using standard score $=[$ (crude score - possible minimum) / (possible maximum - possible minimum) $\times 100$ ] ranged 0 to 100 .

\subsection{Statistical Analysis}

Independent t-test and one-way ANOVA test were used to compare depression death, anxiety death and coping style across sociodemographic and CHD clinical history characteristics. Multiple linear regressions method adjusted to age, sex, education and occupation were constructed to model the relationship between death depression and death anxiety as independent variables, and coping style as a dependent variable. In this model, difference mean of coping style on each group, compared to reference group, was considered as the effect measure of association. P-value $\leq 0.05$ was considered as statistically significant. Statistical analyses were performed, using SPSS 19, and the goodness of fit statistics for construct validity of instrument was calculated by EQS 6.1.

\section{Results}

Table 1 presents the sociodemographic and CHD clinical history of the participants. One hundred fifty nine men (54.3\%), and 134 women (45.7\%) participated in this study, most of whom were married ( $82 \%), 29 \%$ were illiterate, and $32 \%$ were housewives.; $92.2 \%$ and $92 \%$ of the participants did not have ischemic stroke background, or coronary angiography background (Table 1).

Depression death was statistically significant across some variables, including sex, education, occupation, and type of discharge (P value $\leq 0.05)$. Sex, history of hospitalization with CHD and number of hospitalization history with CHD affected anxiety death. The mean (SD) of depression death, anxiety death and coping style across the sociodemographic and CHD clinical history variables is demonstrated in Table 2 in detail.

In univariable model, death depression in the third quartile, compared with reference category, was inversely related to coping style; $\beta$ (95\% CI $)=-1.67(-3.04$ to 0.31$) \mathrm{P}$
Table 1. Descriptive Characteristics of the Participants $(n=293)$

\begin{tabular}{|c|c|}
\hline \multicolumn{2}{|c|}{ Sociodemographic Characteristics ${ }^{\mathbf{a}}$} \\
\hline Age & $60.03(11.03)$ \\
\hline \multicolumn{2}{|l|}{ Sex } \\
\hline Male & $159(54.3)$ \\
\hline Female & $134(45.7)$ \\
\hline \multicolumn{2}{|l|}{ Marital status } \\
\hline Single & $52(17.7)$ \\
\hline Married & $241(52.3)$ \\
\hline \multicolumn{2}{|l|}{ Education } \\
\hline Illiterate & $85(29)$ \\
\hline Elementary & $56(19.1)$ \\
\hline Secondary school & $55(18.8)$ \\
\hline Diploma & $60(20.5)$ \\
\hline Graduated & $37(12.6)$ \\
\hline \multicolumn{2}{|l|}{ Occupation } \\
\hline Worker & $41(14)$ \\
\hline Farmer & $23(7.8)$ \\
\hline Clerk & $66(22.5)$ \\
\hline Military man & $66(22.5)$ \\
\hline Retired & $19(6.5)$ \\
\hline Housewife & $94(32.1)$ \\
\hline Unemployed & $18(6.1)$ \\
\hline Academic career & $6(2)$ \\
\hline \multicolumn{2}{|l|}{ Type of discharge } \\
\hline With insurance & $169(57.3)$ \\
\hline Without insurance & $20(6.8)$ \\
\hline Supplementary insurance & $98(33.4)$ \\
\hline Insurance \& Supplementary insurance & $6(2)$ \\
\hline \multicolumn{2}{|l|}{ CHD clinical History characteristics $^{a}$} \\
\hline \multicolumn{2}{|l|}{ History of coronary angiography } \\
\hline Yes & $24(8.2)$ \\
\hline No & $269(91.8)$ \\
\hline \multicolumn{2}{|l|}{ History of ischemic stroke } \\
\hline Yes & $19(6.5)$ \\
\hline No & $274(93.6)$ \\
\hline \multicolumn{2}{|l|}{ History of CHD hospitalization } \\
\hline Yes & $157(53.6)$ \\
\hline No & $136(46.6)$ \\
\hline \multicolumn{2}{|l|}{ Type of angiography } \\
\hline By stant & $193(66.6)$ \\
\hline Without stant & $71(24.5)$ \\
\hline Coronary artery bypass graft & $26(9)$ \\
\hline
\end{tabular}

${ }^{\mathrm{a}}$ Continuous and Categorical Variables Presented as Mean (SD) and n (\%), respectively.

value $=0.01$. In addition, death anxiety in the fourth quartile was statistically significant compared to the reference group; $\beta(95 \% \mathrm{CI})=1.32$ (0.11 to 2.96) $\mathrm{p}$-value $=0.05$. In the multivariable model, an inverse association was found for the third quartile of death depression; $\beta(95 \% \mathrm{CI})=-1.60(-$ 2.97 to -0.27$)$ P value $=0.02$ (Table 3 ). 
Table 2. Comparison of Death Depression, Death Anxiety and Coping Style Across Explanatory Variables

\begin{tabular}{|c|c|c|c|c|c|c|}
\hline \multirow{2}{*}{ Variables } & \multicolumn{2}{|c|}{ Depression Death } & \multicolumn{2}{|c|}{ Anxiety Death } & \multicolumn{2}{|c|}{ Coping Style } \\
\hline & Mean(SD) & PValue & Mean(SD) & PValue & $\operatorname{Mean}(\mathrm{SD})$ & PValue \\
\hline Sex & & $<0.001^{\mathrm{a}}$ & & $0.01^{\mathrm{a}}$ & & $0.81^{\mathrm{a}}$ \\
\hline Male & $51.2(8.6)$ & & $66.6(13.6)$ & & $52.9(3.9)$ & \\
\hline Female & $60.1(8.8)$ & & $70.6(14.3)$ & & $52.8(4.2)$ & \\
\hline Age category & & 0.4 & & 0.81 & & 0.12 \\
\hline$\leq 55$ & $55.1(10.2)$ & & $67.8(15)$ & & $53.5(4)$ & \\
\hline $56-65$ & $56.1(9.8)$ & & $68.4(14.1)$ & & $52.5(4.2)$ & \\
\hline$\geq 66$ & $57.1(9.2)$ & & $69.1(13.1)$ & & $52.7(3.9)$ & \\
\hline Marital status & & $0.7^{\mathrm{a}}$ & & $0.74^{\mathrm{a}}$ & & $0.4^{\mathrm{a}}$ \\
\hline Single & $56.5(9.1)$ & & $67.9(13.4)$ & & $52.5(3.7)$ & \\
\hline Married & $55.9(9.9)$ & & $68.6(14.2)$ & & $53(4.1)$ & \\
\hline Education & & 0.007 & & 0.72 & & 0.20 \\
\hline Illiterate & $58.6(9.4)$ & & $68.3(12.3)$ & & $52.3(3.4)$ & \\
\hline Elementary & $57.2(10.3)$ & & $70.5(14.9)$ & & $53.1(4.3)$ & \\
\hline Secondary school & $55.5(9.5)$ & & $68.8(14.5)$ & & $52.3(3.8)$ & \\
\hline Graduated & $52.5(10.3)$ & & $67(16)$ & & $54.2(4)$ & \\
\hline Occupation & & $<0.001$ & & 0.74 & & 0.35 \\
\hline Worker & $60.6(9)$ & & $67.7(10.4)$ & & $52(4.3)$ & \\
\hline Farmer & $52.8(7.9)$ & & $68.4(12.6)$ & & $53.4(3.4)$ & \\
\hline Clerk & $54.2(9.9)$ & & $62.3(15.1)$ & & $54(2)$ & \\
\hline Military man & $55.1(6.7)$ & & $66.1(14.3)$ & & $53.5(3.7)$ & \\
\hline Retired & $55.1(6.7)$ & & $65.7(14.7)$ & & $51.8(3.9)$ & \\
\hline Housewife & $62.1(8.7)$ & & $70.7(14.7)$ & & $52.7(4.3)$ & \\
\hline Unemployed & $52.5(9.1)$ & & $66.6(15.5)$ & & & \\
\hline Graduated & $53.1(10.3)$ & & $66.8(14.7)$ & & $54.5(4.4)$ & \\
\hline Type of Discharge & & 0.05 & & 0.33 & & 0.11 \\
\hline With insurance & $56.5(9.9)$ & & $68.9(14.4)$ & & $53.1(4.1)$ & \\
\hline Without insurance & $56.1(6.6)$ & & $63.8(16.1)$ & & $54.1(3)$ & \\
\hline Supplementary insurance & $54.7(9.9)$ & & $68.3(12.8)$ & & $52.4(4.1)$ & \\
\hline No & $55.2(9.9)$ & & $69(14.6)$ & & $53.1(3.7)$ & \\
\hline Yes & $56.8(9.7)$ & & $68(13.6)$ & & $52.7(4.3)$ & \\
\hline Number of years with CHD & & 0.81 & & 0.70 & & 0.07 \\
\hline 0 & $55.4(9.5)$ & & $69.2(14.5)$ & & $53.1(3.5)$ & \\
\hline 1 & $56.8(9.3)$ & & $67.4(15)$ & & $53.7(4.2)$ & \\
\hline 2 & $56.2(11.2)$ & & $67.1(12.4)$ & & $52.3(4.4)$ & \\
\hline$>3$ & $56.5(9.4)$ & & $69.3(13.4)$ & & $51.9(4.4)$ & \\
\hline History of hospitalization with CHD & & 0.6 & & 0.02 & & 0.29 \\
\hline No & $55.7(9.4)$ & & $70.4(13.2)$ & & $52.6(3.7)$ & \\
\hline Yes & $56.3(10)$ & & $66.7(14.5)$ & & $53.1(4.3)$ & \\
\hline Number of hospitalization history with CHD & & 0.56 & & 0.04 & & 0.77 \\
\hline 0 & $55.7(9.4)$ & & $70.4(13.2)$ & & $52.6(3.7)$ & \\
\hline 1 & $57.7(10.4)$ & & $68.8(14.1)$ & & $53.1(3.8)$ & \\
\hline 2 & $56.7(9.9)$ & & $68(13.3)$ & & $53.1(4.3)$ & \\
\hline$>3$ & $55.2(10)$ & & $64.6(15.6)$ & & $53.2(4.6)$ & \\
\hline History of ischemic stroke & & 0.11 & & 0.44 & & 0.57 \\
\hline No & $55.8(9.8)$ & & $68.6(14.1)$ & & $52.8(4.1)$ & \\
\hline Yes & $59.5(9.4)$ & & $66.1(13.9)$ & & $53.4(3.3)$ & \\
\hline History of coronary angiography & & 0.24 & & 0.4 & & 0.17 \\
\hline No & $56.2(9.8)$ & & $68.8(14)$ & & $52.8(4)$ & \\
\hline Yes & $53.8(8.8)$ & & $66.1(14.5)$ & & $54(4.6)$ & \\
\hline
\end{tabular}

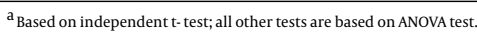


Table 3. Multiple Linear Regression ( $\beta$, 95\% CI) of Death Depression and Death Anxiety with Coping Style in CHD Patients

\begin{tabular}{|c|c|c|c|c|}
\hline \multirow{2}{*}{$\begin{array}{l}\text { Variables } \\
\text { Death depression }\end{array}$} & \multicolumn{2}{|c|}{ Univariable } & \multicolumn{2}{|c|}{ Multivariable $^{a}$} \\
\hline & $\beta^{\mathbf{b}}(\mathbf{9 5} \% \mathbf{C I})$ & P Value & $\beta(\mathbf{9 5} \% \mathbf{C I})$ & P Value \\
\hline Quartile 1 & Reference & & Reference & \\
\hline Quartile 2 & $-0.30(-1.81$ to 1.20$)$ & 0.69 & $-0.27(-1.82$ to 1.20$)$ & 0.69 \\
\hline Quartile 3 & $-1.67(-3.04$ to -0.31$)$ & 0.01 & $-1.60(-2.97$ to -0.27$)$ & 0.02 \\
\hline \multicolumn{5}{|l|}{ Death anxiety } \\
\hline Quartile 1 & Reference & & Reference & \\
\hline Quartile 2 & $0.63(-0.83$ to 2.10$)$ & 0.39 & 0.60 (- 0.84 to 2.09$)$ & 0.40 \\
\hline Quartile 3 & $0.20(-1.16$ to 1.57$)$ & 0.77 & $0.01(-1.36$ to 1.40$)$ & 0.90 \\
\hline Quartile 4 & 1.32 (0.11 to 2.96$)$ & 0.05 & $1.20(-0.25$ to 2.65$)$ & 0.10 \\
\hline
\end{tabular}

${ }^{\mathrm{a}}$ Adjusted for sex, age, education and occupation.

${ }^{\mathrm{b}}$ Difference mean.

\section{Discussion}

To the best of our knowledge, this was the first study to examine the effect of some explanatory variables on death depression, death anxiety and coping style among CHD patients simultaneously in Iran in addition to examining the effect of psychometric determinants on coping style. Our findings revealed that some factors including sex, education, occupation and type of discharge could affect the death depression and sex, history of hospitalization with CHD and number of hospitalization history with CHD on death anxiety. Death depression could be a determinant for coping style.

In non-clinical populations, many researches suggest that occupation does affect health and lower-status work leads to adverse health outcomes (28). Our findings revealed a reverse association between occupation and death depression. We found that homemakers and workers had the most death depression score, respectively. A notable point was the negligible difference between the unemployed and those with high position jobs such as being on a science committee or having an academic career.

In this study, age variable did not contribute to death depression, death anxiety and coping style. Age was an inconsistent determinant in the literature, so in some studies investigators found that death anxiety was not higher in older people compared to the younger $(16,17)$, but other studies found that age monotonically increases with death anxiety level (29).

In this study, lack of association of the studied explanatory variables on coping style was oblivious. In Iran, one of the good evidences about the effect of socioeconomic status on coping style and coping strategy was derived from Isfahan healthy heart program. In that study, the investigators found the significant effects of the education variable on coping strategy, and detected a positive and negative association between the number of education year with adaptive coping strategies and maladaptive coping strategies, respectively; interestingly, the sex variable could modify its effect. In addition, compared to other job positions, they found that manual workers used maladaptive strategies more frequently (30). This difference effect could be the result of the type of studied population. Our study and Isfahan healthy heart program were conducted on a clinical and non-clinical population, respectively, so type of studied population could be considered as an interaction variable.

We found that increasing the level of death depression led to a decrease in coping style. The presence of severe death depression level could worsen the coping style of the patients with their disease; for example, non-adherence of treatment may occur, indicating avoidant coping style (31). Some other studies found that anxiety could be considered as a prohibitive factor to efficient hypertension management $(32,33)$. In one study, investigators argued that coping style of coronary artery disease (CAD) patients was independent of emotional distress indicators, including depression and anxiety, meaning that regardless of whether CAD patients acknowledge the low level of emotional distress, those who use a repressive coping style were more at risk of clinical events (34).

We found that history of ischemic stroke and history of coronary angiography were not related to death depression, death anxiety and coping style, but hospitalization was a determinant of a decrease in anxiety level. Pajak et al. found that the prevalence of depression and anxiety is 
high among CHD patients in general, and indicated that no history of invasive treatment is associated with more frequent depression and anxiety in hospitalized CHD patients (35).

There are a few possible reasons for the low level of depression and anxiety in CHD patients following a hospitalization. First, after hospitalization, the patient receives an efficient social support from the family, friends, the hospital physician and the nurse, which could affect healthrelated quality of life and in-turn lead to a decrease in anxiety and depressive symptoms. Secondly, up to $75 \%$ of the patients had almost mild diseases, and such situation in disease severity could influence the depression or anxiety level.

Some points could strengthen our study. We used CHD clinical history factors and found that they could be remarkable determinants in this context. The study samples were collected from several hospitals, which helps generalizing the results to a bigger plausible population. However, this study had some limitations that should be considered. Firstly, some of the important determinants such as spirituality, self-esteem or religious beliefs that are related to death depression or death anxiety were not considered. Secondly, in cross- sectional studies, no time order or causality can be proved so useful coping strategies may lead to lower depression and anxiety levels (34). Longitudinal studies are needed to clarify the temporality of this association. Thirdly, as data collection was done by a self-administered questionnaire, which could induce some measurement biases, a matter that should be considered when interpreting the findings.

In summary, this study provided evidence for an increase in death depression, with low educational level and homemakers and workers among CHD patients. Hospitalization due to CHD could be a determinant of death anxiety level. The results point to the importance of the sociodemographic and CHD clinical history characteristics to minimize unfavorable psychometric conditions, including death depression and death anxiety among CHD patients. Psychometric conditions could affect the coping style of CHD patients.

\section{Acknowledgments}

This work was derived from Koroush Rashidi dissertation and supported by the Tabriz University of Medical Sciences.

\section{Footnotes}

Authors' Contribution: Hadi Hassankhani and Koroush Rashidi conceived and designed the evaluation. Er- fan Ayubi performed the statistical analysis. Hadi Hassankhani, Koroush Rashidi, Farahnaz Abdullahzadeh and Shadi Ozairi performed the clinical data analysis and interpreted them. Hadi Hassankhani, Koroush Rashidi and Azad Rahmani drafted the manuscript. Hadi Hassankhani, Koroush Rashidi and Farahnaz Abdullahzadeh revised it critically for important intellectual content.

Declaration of Interest: The authors declare that they have no competing interests.

Funding/Support: This work was derived from Koroush Rashidi dissertation and supported by the Tabriz University of Medical Sciences.

\section{References}

1. Nichols M, Townsend N, Scarborough P, Rayner M. Cardiovascular disease in Europe: epidemiological update. Eur Heart J. 2013;34(39):302834. doi: 10.1093/eurheartj/eht356. [PubMed: 24014390].

2. Esteghamati A, Meysamie A, Khalilzadeh O, Rashidi A, Haghazali M, Asgari F, et al. Third national Surveillance of Risk Factors of NonCommunicable Diseases (SuRFNCD-2007) in Iran: methods and results on prevalence of diabetes, hypertension, obesity, central obesity, and dyslipidemia. BMC Public Health. 2009;9:167. doi: 10.1186/1471 2458-9-167. [PubMed: 19480675].

3. Levin SN, Hajduk AM, McManus DD, Darling CE, Gurwitz JH, Spencer FA, et al. Cognitive status in patients hospitalized with acute decompensated heart failure. Am Heart J. 2014;168(6):917-23. doi: 10.1016/j.ahj.2014.08.008. [PubMed: 25458656].

4. Pfeifer PM, Ruschel PP, Bordignon S. Coping strategies after heart transplantation: psychological implications. Braz J Cardiovasc Surg. 2013;28(1):61-8.

5. Alvarado KA, Templer DI, Bresler C, Thomas-Dobson S. Are death anxiety and death depression distinct entities?. OMEGA-J Death Dying. 1993;26(2):113-8.

6. Lehto RH, Stein KF. Death anxiety: an analysis of an evolving concept. Res Theory Nurs Pract. 2009;23(1):23-41. [PubMed: 19418886].

7. Sherman DW, Norman R, McSherry CB. A comparison of death anxiety and quality of life of patients with advanced cancer or AIDS and their family caregivers. J Assoc Nurses AIDS Care. 2010;21(2):99-112. doi: 10.1016/j.jana.2009.07.007. [PubMed: 20006525].

8. Neimeyer RA, Pfeiffer AM. Evaluation of suicide intervention effectiveness. Death Stud. 1994;18(2):131-66. doi: 10.1080/07481189408252648. [PubMed: 10133100].

9. Tomas-Sabado J, Limonero JT, Templer DI, Gómez-Benito J. The death depression scale-revised. Preliminary empirical validation of the Spanish form. Omega-J Death Dying. 2005;50(1):43-52.

10. Carver CS, Scheier MF, Weintraub JK. Assessing coping strategies: a theoretically based approach. J Pers Soc Psychol. 1989;56(2):267-83. [PubMed: 2926629].

11. Donnellan C, Hevey D, Hickey A, O'Neill D. Defining and quantifying coping strategies after stroke: a review. J Neurol Neurosurg Psychiatry. 2006;77(11):1208-18. doi: 10.1136/jnnp.2005.085670. [PubMed: 17043290].

12. Taylor SE, Stanton AL. Coping resources, coping processes, and mental health. Annu Rev Clin Psychol. 2007;3:377-401. doi: 10.1146/annurev.clinpsy.3.022806.091520. [PubMed:17716061].

13. Albert CM, Chae CU, Rexrode KM, Manson JE, Kawachi I. Phobic anxiety and risk of coronary heart disease and sudden cardiac death among women. Circulation. 2005;111(4):480-7. doi: 10.1161/01.CIR.0000153813.64165.5D. [PubMed: 15687137]. 
14. Martens EJ, de Jonge P, Na B, Cohen BE, Lett H, Whooley MA. Scared to death? Generalized anxiety disorder and cardiovascular events in patients with stable coronary heart disease:The Heart and Soul Study. Arch Gen Psychiatry. 2010;67(7):750-8. doi: 10.1001/archgenpsychiatry.2010.74. [PubMed: 20603456].

15. Ziegelstein RC, Fauerbach JA, Stevens SS, Romanelli J, Richter DP, Bush DE. Patients with depression are less likely to follow recommendations to reduce cardiac risk during recovery from a myocardial infarction. Arch Intern Med. 2000;160(12):1818-23. [PubMed: 10871976].

16. Abdel-Khalek AM, Lester D. Death anxiety as related to somatic symptoms in two cultures. Psychol Rep. 2009;105(2):409-10. doi: 10.2466/PR0.105.2.409-410. [PubMed: 19928602].

17. Eshbaugh E, Henninger W. Potential Mediators of the Relationship Between Gender and Death Anxiety. Individual Differences Res. 2013;11(1).

18. Furer P, Walker JR. Death anxiety: A cognitive-behavioral approach.J Cogn Psychother. 2008;22(2):167-82.

19. Glasscock DJ, Andersen JH, Labriola M, Rasmussen K, Hansen CD. Can negative life events and coping style help explain socioeconomic differences in perceived stress among adolescents? A cross-sectional study based on the West Jutland cohort study. BMC Public Health. 2013;13:532. doi: 10.1186/1471-2458-13-532. [PubMed: 23724872].

20. Fenix JB, Cherlin EJ, Prigerson HG, Johnson-Hurzeler R, Kasl SV, Bradley EH. Religiousness and major depression among bereaved family caregivers: a 13-month follow-up study. J Palliat Care. 2006;22(4):286-92. [PubMed: 17263056].

21. Ramirez SP, Macedo DS, Sales PM, Figueiredo SM, Daher EF, Araujo SM, et al. The relationship between religious coping, psychological distress and quality of life in hemodialysis patients. J Psychosom Res. 2012;72(2):129-35. doi: 10.1016/j.jpsychores.2011.11.012. [PubMed 22281454].

22. Tremblay PF, King PR. State and trait anxiety, coping styles and depression among psychiatric inpatients. Canadian $J$ Behav Sci. 1994;26(4):505.

23. Templer DI. The construction and validation of a Death Anxiety Scale. J Gen Psychol. 1970;82(2d Half):165-77. doi: 10.1080/00221309.1970.9920634. [PubMed: 4394812].

24. Lazarus RS, Folkman S. Stress, Appraisal, and Coping. New York: Springer; 1984
25. Abdel-Khalek A, Beshai JA, Templer DI. The structure of Templer's Death Anxiety Scale among Egyptian students. Psychol Rep. 1993;72(3 Pt 1):920-2. doi: 10.2466/pro.1993.72.3.920. [PubMed: 8332695].

26. Ray R, Raju M. Attitude towards euthanasia in relation to death anxiety among a sample of 343 nurses in India. Psychol Rep. 2006;99(1):206. doi: 10.2466/pro.99.1.20-26. [PubMed: 17037446].

27. Tavakoli MA, Ahmadzadeh B. Investigation of validity and reliability of templer death anxiety Scale. Thought \& Behav Clin Psychol. 2011;6(21):72-80.

28. Clougherty JE, Souza K, Cullen MR. Work and its role in shaping the social gradient in health. Ann N Y Acad Sci. 2010;1186:102-24. doi: 10.1111/j.1749-6632.2009.05338.x. [PubMed: 20201870].

29. Pollak JM. Correlates of death anxiety: A review of empirical studies. OMEGA-J Death Dying. 1980;10(2):97-121.

30. Roohafza H, Sadeghi M, Shirani S, Bahonar A, Mackie M, Sarafzadegan N. Association of socioeconomic status and life-style factors with coping strategies in Isfahan Healthy Heart Program, Iran. Croat Med J. 2009;50(4):380-6. [PubMed: 19673038].

31. Realdi A, Favaro A, Santonastaso P, Nuti M, Parotto E, Inverso G, et al. Obsessive-Compulsive and Post Traumatic Avoidance Symptoms Influence the Response to Antihypertensive Therapy: Relevance in Uncontrolled Hypertension. Pharmaceuticals (Basel). 2009;2(3):82-93. doi: 10.3390/ph2030082. [PubMed: 27713226].

32. Garg JP, Elliott WJ, Folker A, Izhar M, Black HR, Rush University Hypertension Service . Resistant hypertension revisited: a comparison of two university-based cohorts. Am J Hypertens. 2005;18(5 Pt 1):619-26. doi: 10.1016/j.amjhyper.2004.11.021. [PubMed: 15882544].

33. Isaksson $\mathrm{H}$, Konarski $\mathrm{K}$, Theorell $\mathrm{T}$. The psychological and social condition of hypertensives resistant to pharmacological treatment. Soc Sci Med. 1992;35(7):869-75.

34. Denollet J, Martens EJ, Nyklicek I, Conraads VM, de Gelder B. Clinical events in coronary patients who report low distress: adverse effect of repressive coping. Health Psychol. 2008;27(3):302-8. doi:10.1037/02786133.27.3.302. [PubMed: 18624593].

35. Pajak A, Jankowski P, Kotseva K, Heidrich J, de Smedt D, De Bacquer $\mathrm{D}$, et al. Depression, anxiety, and risk factor control in patients after hospitalization for coronary heart disease: the EUROASPIRE III Study. Eur J Prev Cardiol. 2013;20(2):331-40. doi: 10.1177/2047487312441724. [PubMed: 22396247]. 